\title{
A Case Study of Integrating Interwise: Interaction, Internet Self-Efficacy, and Satisfaction in Synchronous Online Learning Environments
}
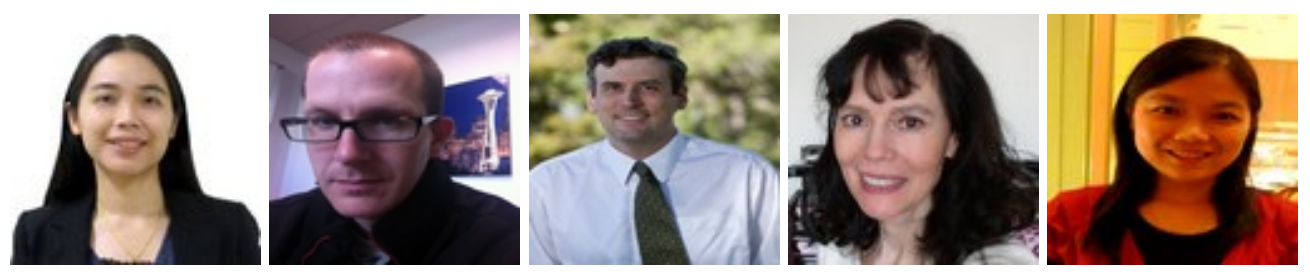

Yu-Chun Kuo ${ }^{1}$, Andrew E. Walker ${ }^{2}$, Brian R. Belland ${ }^{2}$, Kerstin E. E. Schroder ${ }^{3}$, and Yu-Tung Kuo ${ }^{4}$ ${ }^{1}$ Jackson State University, USA, ${ }^{2}$ Utah State University, USA, ${ }^{3}$ University of Alabama at Birmingham, USA, ${ }^{4}$ National Chiao Tung University, Taiwan

\section{Abstract}

This paper reports research on the implementation of a web-based videoconferencing tool (Interwise) for synchronous learning sessions on an industrial technology course offered through a university in northern Taiwan. The participants included undergraduate students from the same course offered in two different semesters. We investigated students' perceptions of interactions with the instructor and fellow students, their confidence in utilizing the Internet (Internet self-efficacy), and the satisfaction level that students perceived throughout the learning process with Interwise. We also examined the effect of interactions and Internet self-efficacy on student satisfaction. Data collected through paper-based and online surveys were analyzed using correlation and multiple regression. The results revealed that overall, learners perceived Interwise as a tool that was moderately easy to use for synchronous learning. Learners seemed to prefer using the Interwise features, such as emotion icons, talk, or raise hand, to interact with their instructor. Learners had high confidence in gathering data or getting support through the Internet, but low confidence in resolving Internet related problems. Both learner-learner and learner-instructor interactions were significant predictors of student satisfaction, while Internet self-efficacy did not significantly contribute to satisfaction. Learner-instructor interaction was found to be the strongest predictor of student satisfaction.

Keywords: Learner-learner interaction; learner-instructor interaction; Internet self-efficacy; synchronous learning; satisfaction; Interwise 


\section{Introduction}

Distance education has become a popular alternative to traditional, face-to-face instruction in many countries throughout the world. In distance education, information and communication technologies (ICTs) can help bridge the separation of distance and time between teachers and students by enabling interaction (Moore \& Kearsley, 1996). ICTs are digital tools or sources used to manipulate, distribute, and create information (Apena, 2012; Olusola \& Alaba, 2011). ICTs include traditional (e.g., radio, television) and new technologies such as the Internet, the World Wide Web (WWW), teleconferencing, interactive CDs, virtual realities, hardware, and software (Apena, 2012; Olusola \& Alaba, 2011; Wang \& Woo, 2007). These tools manipulate and process information but also facilitate communication (Apena, 2012; Koustourakis, Panagiotakopoulos, \& Vergidis, 2008). ICT integration is a multi-faceted process and includes micro- (e.g., instructional, class) and macro- (e.g., state, institutional, organisational) levels (Altun, Kalaycı, \& Avci, 2011; Wang, 2008). This study exemplifies micro-levels of ICT integration.

Recent improvement in ICTs has made the use of synchronous instruction more popular than previously. Synchronous and asynchronous learning differ in terms of interaction and the type of support that may be required ( $\mathrm{Ng}, 2007)$. The advantages of using synchronous technology tools include real-time communication between the instructor and learners or among learners, immediate response from the instructor for clarification on learners' questions, decrease of travelling time, and simulated experience of a real classroom learning setting (Salmon, 2000). Studies have shown that integration of ICTs enhances students' interaction with their classmates and instructor, which in turn helps create a satisfying learning experience (Altun, Kalaycl, \& Avci, 2011; Snowball \& Mostert, 2010; Wang, 2008).

Learners' confidence in using ICTs may affect their learning experiences in distance learning. According to a report by Taiwan's Executive Yuan (2011) on Taiwanese ICT use and digital opportunities, more than $72 \%$ of the 12 -and-older population have access to a computer and the Internet. The Internet-access rate is associated with education level. Although many use the Internet in Taiwan, the level of self-efficacy towards the Internet may vary from one person to another. Internet self-efficacy reflects one's confidence in performing Internet-related tasks, which may be especially important for online learners, who need to possess a certain level of Internet skills to proceed with their learning successfully. Although interaction has been identified as a critical component of student satisfaction in distance learning (Kuo, Walker, Belland, \& Schroder, 2013), the impact of Internet self-efficacy on student satisfaction is not clear (Puzziferro, 2008; Rodriguez Robles, 2006). In addition, depending on the types of technology tools utilized in distance learning, students' learning experiences would differ. Each type of technology tool is developed with its own purpose for teaching and learning. For example, WebCT is designed for course delivery and management (Rogerson-Revell, 
2007). Wikis are used to increase communication and collaboration among students (Bradley, Lindstrom, \& Rystedt, 2010; Carter, 2009).

The web-based conferencing tool used in this study, Interwise, allows an instructor to provide a live lecture or presentation to their students. Real time communication between instructor and students is enhanced through features such as audio, video, whiteboard, and hands-on functions (AT\&T, 2013). Studies on the use of Interwise in teaching and learning are limited (Ng, 2007; Skylar, 2009). This study investigated the influence of interaction and Internet self-efficacy on Taiwanese students' satisfaction in synchronous learning environments through Interwise.

\section{Literature Review}

First, we provide an overview of three major constructs in online education interaction, Internet self-efficacy, and student satisfaction. In particular, we summarize previous research on the relationships between the independent variables (i.e., interaction, Internet self-efficacy) and dependent variables (i.e., student satisfaction) in online education settings.

\section{Interaction.}

Interaction is important in all forms of education, regardless of whether technology is involved. Interaction in traditional classroom learning focuses on the dialogues between instructors and students. Due to the rapid development of ICTs, the concept of interaction has been expanded to distance learning environments within which a wide range of mediation takes place. The nature of interaction occurring in a traditional classroom may not be possible, and consequently the effectiveness of teaching and learning might be lowered to a certain extent.

The most prominent framework of interaction includes three major constituents: learner-instructor interaction, learner-learner interaction, and learner-content interaction (Moore, 1989). Although other types of interaction are often addressed by researchers from different perspectives, Moore's interaction model continues to dominate research on interaction in distance learning environments (Moore, 1989; Northrup, Lee, \& Burgess, 2002). For example, Northrup, Lee, and Burgess (2002) categorized interaction within online learning into four elements: content interaction, conversation and collaboration, meta-cognitive skills, and need for support. Focusing on the social, pedagogical, and economic impact, Anderson (2003) extended the definition by proposing six types of interaction: teacher-teacher, teacher-content, and contentcontent, in addition to the three types of interactions described by Moore. Muirhead and Juwah (2004) considered the previous definitions and proposed that interaction is a dialogue or discourse or event that occurs between participants or objects through the synchronous or asynchronous mediation of responses, feedback, or technology.

Among the three types of interaction, learner-instructor interaction and learner-learner 
interaction are easy to explain and understand. The former involves a two-way communication between the instructor and learners, and the latter refers to a two-way communication between learners (Moore, 1989). Both are regarded as essential factors in traditional learning and distance learning settings. For most learners, desired learner-instructor interaction includes immediate feedback and professional guidance from the instructor, especially at the points of application and evaluation. Learnercontent interaction refers to an internal process in which learners elaborate and reflect on the course content (Moore, 1989).

This study focused on learner-learner interaction and learner-instructor interaction since these two types of interaction were identified as most important to online learners in previous research (Battalio, 2007; Bolliger \& Martindale, 2004; J ung, Choi, Lim, \& Leem, 2002). Instead of measuring the amount of interaction that students actually had with their instructor or classmates, this study investigated the interactions that students perceived from their communications with the instructor and their fellow students, but not how much interaction there really was. Therefore, a self-report that reflected student perceptions towards interaction was utilized to measure learner-learner interaction and learner-instructor interaction.

\section{Internet self-efficacy.}

People's confidence in their ability to perform certain tasks, or self-efficacy, has long been examined to predict the extent to which they will engage in the task (Bandura, 1977). Internet self-efficacy refers to one's belief in his or her capability to organize and execute Internet-related actions to accomplish online tasks or assignments (Eastin \& LaRose, 2000). Eastin and LaRose (2000) claimed that previous studies did not develop a measure of self-efficacy for overall Internet usage, but a measure specific to a certain type of Internet-related task (e.g., using a browser, writing HTML, moving bookmarks). Thus, the Internet self-efficacy scale proposed by Eastin and LaRose (2000) is a selfreport that assesses one's judgment of their ability to apply Internet skills more widely, including understanding of Internet software and hardware, finding information, troubleshooting search problems, and confidence in learning advanced Internet skills.

Internet self-efficacy is positively related to previous Internet experience and Internet use, but negatively related to Internet stress (Eastin \& LaRose, 2000). People with positive attitudes toward technologies are likely to have higher Internet self-efficacy, compared to those with negative attitudes toward technologies. Internet training is helpful to improve learners' Internet self-efficacy, especially for those with positive attitudes toward technologies, and those with low computer anxiety (Torkzadeh, Chang, \&Demirhan, 2006; Torkzadeh \&Van Dyke, 2002).

\section{Student satisfaction.}

Referring to student perceptions of the extent to which their learning experiences were helpful and enjoyable, student satisfaction is a critical indicator of instructional quality. 
Student satisfaction is strongly related to cognitive learning outcomes (e.g., performance, achievement) (Biner, Bink, Huffman, \& Dean, 1997; Wang \& Ku, 2010). It is worthwhile to investigate student satisfaction due to its relation to retention, loyalty to a program, and student performance (Ali \& Ahmad, 2011; Allen \& Seaman, 2003; Yukselturk \& Yildirim, 2008). It provides valuable information to instructors or administrators on what could be improved to a program or an online course (Biner, Bink, Huffman, \& Dean, 1997; Bolliger \& Martindale, 2004). Student satisfaction in this study was measured through student self reports in order to obtain student perceptions of the level of satisfaction towards the synchronous sessions.

\section{Interaction, Internet self-efficacy, and student satisfaction.}

Interaction is a pivotal variable that has an impact on student satisfaction in distance learning environments (Bray, Aoki, \& Dlugosh, 2008; Kuo, Walker, Schroder, \& Belland, 2014; Rodriguez Robles, 2006). For example, Offir, Lev, and Bezalel (2008) found the interaction level in a synchronous class to significantly predict the effectiveness of the class. Although the literature indicates that both learner-instructor interaction and learner-learner interaction are significant predictors of student satisfaction, it is unclear which type of interaction is most important in evaluating students' experiences in which type of distance learning environments. Some research indicated learner-instructor interaction as the best predictor of student satisfaction while others identified learnerlearner interaction as the best predictor of student satisfaction (Bolliger \& Martindale, 2004; Rodriguez Robles, 2006). It seems that learner-instructor interaction would be most influential to student satisfaction in a course that involves a high percentage of instructor-led instructions. When a course is designed applying learner-centered approaches to engage students through a series of collaborative activities, learnerlearner interaction appears to be most critical to one's learning experiences (Battalio, 2007).

The findings of the relationship between Internet self-efficacy and learning results such as performance and satisfaction are inconclusive. Some studies indicated that Internet self-efficacy positively correlates with or predicts students' performance in web-based learning environments (DeTure, 2004; J oo, Bong, \& Choi, 2000; Thompson, Meriac, \& Cope, 2009). For example, students with higher Internet self-efficacy were found to have better information searching skills and learn better than those with lower Internet self-efficacy (Tsai \& Tsai, 2003). However, little is known about the effect of Internet self-efficacy on student satisfaction in distance education. Only a few studies investigated the relationship between Internet self-efficacy and satisfaction, and showed that Internet self-efficacy is not significantly correlated with or predictive of satisfaction in web-based learning environments (Puzziferro, 2006; Puzziferro, 2008; Rodriguez Robles, 2006). Lim (2001) found that Internet experiences in a class correlate positively with student satisfaction. More research is needed to examine the role of Internet selfefficacy for student satisfaction in online synchronous learning. 
No previous study has investigated the effect of learner-learner interaction, learnerinstructor interaction, and Internet self-efficacy on student satisfaction with the implementation of Interwise in web-based learning. It appears to be worthwhile to identify the relationships of satisfaction in terms of interaction and Internet self-efficacy. The contribution of two types of interaction and Internet self-efficacy in predicting student satisfaction in online synchronous settings was of particular interest in this research. In addition, learners' perceptions of using Interwise were explored.

\section{Methodology}

This study examined the influence of two types of interaction and Internet self-efficacy on the satisfaction of students enrolled in a course involving two synchronous learning sessions. The study investigated the relationships between predictors (learner-learner interaction, learner-instructor interaction, and Internet self-efficacy) and student satisfaction. A model for significant prediction of student satisfaction in terms of interactions and Internet self-efficacy was expected. Further, the contribution of individual predictors in student satisfaction was of interest.

\section{Research Questions}

1. To what extent does each independent variable (learner-instructor interaction, learner-learner interaction, and Internet self-efficacy) correlate with student satisfaction?

2. Are learner-learner interaction, learner-instructor interaction, and Internet selfefficacy significant predictors of student satisfaction?

3. What is the unique contribution of each significant independent variable to student satisfaction?

\section{Setting and Participants}

Participants in this study were students in three sections of a course entitled "Introduction to Transportation Technology" offered by the Department of Industrial Technology Education (ITE) at a university in northern Taiwan in fall 2009 and spring 2010. There were two class sections in spring 2010, and one class section in fall 2009. Out of 65 students who attended the class, 57 students responded to the survey. The return rate was $88 \%$.

Table 1 shows the students' demographic information. There were more male respondents than female respondents. All respondents were single with their ages ranging from 18 to 24 years old. Most respondents had been using computers for more than 6 years. Ninety-five percent of the respondents had their own computer. 
Table 1

Student Demographic Information

\begin{tabular}{lll}
\hline & Frequency & Percentage \\
\hline Gender & 38 & 66.7 \\
Male & 19 & 33.3 \\
Female & & \\
Marital status & 57 & 100 \\
Single & & \\
Age & 6 & 10.5 \\
18 & 19 & 33.3 \\
19 & 5 & 8.8 \\
20 & 14 & 24.6 \\
21 & 8 & 14.0 \\
22 & 4 & 7.0 \\
23 & 1 & 1.8 \\
24 & & \\
Grade level & 24 & 42.1 \\
Freshman & 3 & 5.3 \\
Sophomore & 28 & 49.1 \\
Junior & 2 & 3.5 \\
Senior & & \\
Years of using computers & 4 & 7.0 \\
1-3 & 11 & 19.3 \\
$4-6$ & 22 & 38.6 \\
$7-9$ & 11 & 19.3 \\
10-12 & 9 & 15.8 \\
Above 12 years & & \\
Own a personal computer & 54 & 94.7 \\
Yes & 3 & 5.3 \\
No & & \\
\hline
\end{tabular}

\section{Materials}

This course included 14 weeks of traditional face-to-face sessions and 2 weeks of online synchronous sessions. The online synchronous sessions were facilitated through use of the Interwise software.

Interwise is a Web conferencing tool that provides individuals the opportunities of realtime communications by voice and graphics over the Internet. The Interwise platform includes features that allow a two-way video connection between the moderator and participants. The instructor acts as a moderator who monitors the conversations between him or her and the participants, by submitting questions, tests, or surveys to participants. The instructor can display PowerPoint slides, videos, or images on the whiteboard.

When leading a synchronous meeting, the instructor can enable students to point at or 
mark up the content on the screen displayed in real-time. By pressing the "raise a hand" tab, students are able to ask a question verbally. Emotion icons are provided for students to express themselves. The whole live learning session is available to students through recording (AT\&T Connect, 2010). Figure 1 shows the Interwise interface when students underwent the online synchronous sessions.

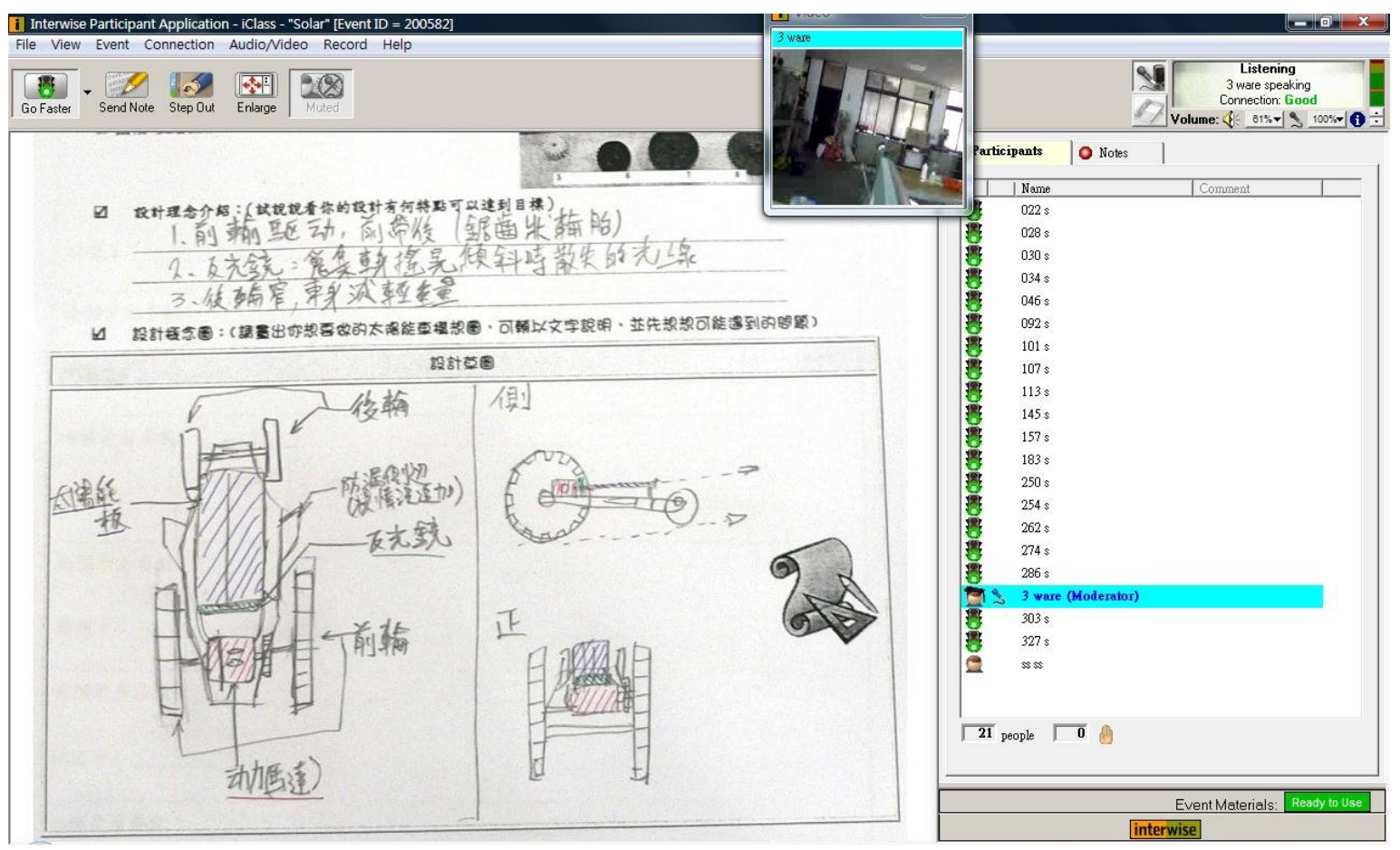

Figure 1. Interwise interface in the online synchronous sessions.

\section{Instrument}

A questionnaire was designed that includes four major sections: demographic information, Interwise usage, student perceptions of two types of interactions, Internet self-efficacy, and student satisfaction. The demographic information covers six items, which consisted of gender, marital status, age, grade level, years of using computers, and possession of a personal computer (Please see Table 1). Interwise usage contains questions in relation to learners' perceptions of ease of using Interwise and preference for some featured functions. To measure student perceptions of interaction and student satisfaction, the researchers modified the items of the questionnaire from a previous study (Kuo, Eastmond, Schroder, \& Bennett, 2009), which was developed to measure student perceptions of interactions and satisfaction, with good reliability and validity information. The Cronbach's alpha coefficient values for interactions and satisfaction scales from the previous study ranged from .795 to .901 .

Both interaction and satisfaction scales are a 5-point Likert scale ranging from 1 (strongly disagree) to 5 (strongly agree). The interaction scale includes two sections, 
which are "Learner-learner interaction," and "Learner-instructor interaction" subscales, with seven and eight items respectively. The learner-learner interaction subscale measures the extent to which students perceived that they communicated with fellow students through idea sharing, comments, or working on the same activities or projects. The learner-instructor interaction subscale measures the extent to which students perceived interacting with the instructor by answering questions, getting feedback, or being encouraged to express their thoughts. The student satisfaction scale includes five items regarding students' perceptions of the value of their learning experiences to their own professional development, and their willingness to take similar courses in the future. Slight wording changes were made to fit the context of this study where the Interwise platform was utilized. The Cronbach's coefficient alpha values for each type of the interactions and satisfaction ranged from .852 to .898 (please see Table 3).

The Internet self-efficacy scale in this research was developed by Eastin and LaRose (2000). This measurement with eight items is a seven-point scale that ranges from 1 (very unlikely) to 7 (very likely). This scale was found to be reliable and internally consistent with a Cronbach's coefficient alpha value at .93. The construct validity of this scale was examined and proved valid.

\section{Procedures}

The instructor presented the Interwise tool to students and showed how it worked one week before online synchronous sessions started, to ensure that students were able to operate the software in their own computers. The processes of installing Interwise and using other necessary supplements such as a webcam, a headset, and so on were addressed by the instructor and teaching assistant. Three days before the implementation of Interwise sessions, the instructor and the teaching assistant provided several meeting opportunities to help each student with the installation of Interwise as well as the tests of voice and visual functions, to make sure that Interwise could be used by each student.

The questionnaire was translated to Chinese by the researchers since the students' native language is Chinese. The translated questionnaire was administered to students at the end of spring semester. Before distributing the questionnaire, the researchers contacted the instructor to obtain permission to distribute the survey. Two forms of the survey with the same content were distributed: a paper-based version and an electronic version. The paper-based survey was distributed to the students during the class one week before the end of J une 2010, since the students still attended the face-to-face sessions. In terms of convenience of reaching students who had finished the course earlier in the previous semester, the electronic version of the survey was emailed to the students who had finished their class in the fall semester of 2009.

\section{Data Analysis}

All data analyses were conducted using SPSS 16.0 for Windows software package. 
Descriptive analyses were performed to represent basic student information as well as the average scores for learner-learner interaction, learner-instructor interaction, Internet self-efficacy, and satisfaction. Correlation analysis was used to understand the relationship between the two types of interaction, Internet self-efficacy, and student satisfaction. In addition, correlation analysis served as a preliminary analysis of examining possible multicollinearity problems before any multiple regression analyses were performed. Multiple regression analyses were performed to investigate the combined contribution of predictors towards student satisfaction.

\section{Findings}

Table 2 shows students' perceptions of using Interwise. Overall, students agreed that it was moderately easy to use Interwise $(\mathrm{M}=3.28)$. When asked whether they liked features such as talk, Interwise whiteboard, emotion icons, send note, and raise hand, the average scores fall within 3 and 4 . Emotion icons seemed to be the most preferable features for students, followed by the raise hand feature. Students favored using talk features least.

Table 2

Interwise Usage

\begin{tabular}{lll}
\hline Interwise usage & $\mathrm{M}$ & $\mathrm{SD}$ \\
\hline Ease of using Interwise & 3.28 & 1.06 \\
Talk feature & 3.23 & 1.07 \\
Interwise whiteboard & 3.35 & 0.99 \\
Emotion icons (laugh, etc.) & 3.87 & 1.07 \\
Send note feature & 3.42 & 1.03 \\
Raise hand feature & 3.61 & 1.14 \\
\hline
\end{tabular}

Note. This is a 5-point likert scale with a minimum score of 1 and a maximum score of 5 .

Table 3 reveals the average scores on the two types of interaction, Internet self-efficacy, and student satisfaction. The average scores of learner-learner interaction and learnerinstructor interaction are both higher than the mid-point score 3. The average score of Internet self-efficacy is 4.66 , which is larger than the mid-point score 4 . This means that most respondents agreed that they had a certain amount of interaction with their instructor and fellow students. It appears that most respondents were confident in performing Internet-related tasks. The average score of 3.27 indicates that overall the respondents were moderately satisfied with the class implemented through the use of Interwise. 
Table 3

Descriptive Information of the Scales

\begin{tabular}{llll}
\hline Interactions \& satisfaction & $\mathrm{M}$ & $\mathrm{SD}$ & $\alpha$ \\
\hline Learner-learner interaction (7 items) & 3.04 & 0.74 & 0.852 \\
Learner-instructor interaction (8 items) & 3.35 & 0.67 & 0.859 \\
Internet self-efficacy (8 items) & 4.66 & 0.82 & 0.860 \\
Satisfaction (5 items) & 3.27 & 0.80 & 0.898 \\
\hline
\end{tabular}

Note. The minimum score for all scales is 1.The maximum score for the interaction and satisfaction scales is 5 but 7 for the Internet self-efficacy scale.

Research Question 1: To what extent does each independent variable (learner-instructor interaction, learner-learner interaction, and Internet self-efficacy) correlate with student satisfaction?

Table 4 depicts the relationships among the two types of interactions, Internet selfefficacy, and satisfaction. The two types of interactions and Internet self-efficacy are all positively related to satisfaction. There was a significant correlation between the learner-learner interaction and satisfaction $(\mathrm{r}=.559, \mathrm{p}<.01)$. The level of interaction between learners and the instructor is significantly correlated with satisfaction $(r=.747$, $\mathrm{p}$ <.01). The correlation between Internet self-efficacy and satisfaction was weaker $(\mathrm{r}=$ $.398, \mathrm{p}<.01)$. As the interactions of learners with their fellow students and the instructor increase, the level of satisfaction increases. The more confident learners were in performing Internet related tasks, the higher level of satisfaction they perceived.

Table 4

Correlations Among Independent Variables and Student Satisfaction

\begin{tabular}{lllll}
\hline & Learner-learner & $\begin{array}{l}\text { Learner- } \\
\text { instructor }\end{array}$ & $\begin{array}{l}\text { Internet self- } \\
\text { efficacy }\end{array}$ & Satisfaction \\
\hline Learner-learner & - & $.462^{* *}$ & .160 & $.559^{* *}$ \\
Learner-instructor & & - & $.523^{* *}$ & $.747^{* *}$ \\
Internet self-efficacy & & - & $.398^{* *}$ \\
Satisfaction & & & - \\
\hline
\end{tabular}

${ }^{*} \mathrm{p}<.05 . * * \mathrm{p}<.01 . * * * \mathrm{p}<.001$

Research Question 2: Are learner-learner interaction, learner-instructor interaction, and Internet self-efficacy significant predictors of student satisfaction? 
Based on the correlation values among independent variables, no potential multicollinearity problems were shown, since all correlations among predictors were lower than .80, which indicated that the three predictors were devoid of multicollinearity. Before multiple regression analysis was performed, the assumptions of linearity, homoscedasticity, and normality of residuals were tested to make sure no violations were made against the requirements of regression analysis.

Table 5

The Variance in Satisfaction Explained by Three Predictor Variables

\begin{tabular}{lllll} 
Model & $\mathrm{R}$ & $\mathrm{R}^{2}$ & Adj. $\mathrm{R}^{2}$ & $\begin{array}{l}\text { SE of the } \\
\text { estimate }\end{array}$ \\
\hline 1 & $.786^{\mathrm{a}}$ & .618 & .596 & .510 \\
\hline
\end{tabular}

The model summary (see Table 5) revealed that $61.8 \%$ of the variance in satisfaction was explained by the predictors learner-learner interaction, learner-instructor interaction, and Internet self-efficacy. This multiple regression model was significant $(\mathrm{F}(3,53)=28.57, \mathrm{p}<.001)$, which indicates that, overall, the combination of interactions and Internet self-efficacy significantly predicted satisfaction.

There was no multicollinearity for the predictors with tolerances larger than .10 and VIFs smaller than 10 (see Table 6). Three $\beta$-values were all positive, indicating there were positive relationships between each type of the interactions and satisfaction. The predictors learner-learner interaction $(\mathrm{t}(53)=2.869, \mathrm{p}<.01)$ and learner-instructor interaction $(t(53)=5.361, p<.001)$ significantly contributed to the model while Internet self-efficacy $(t(53)=0.414, p>.05$ ) was not a significant predictor in the model. Learner-instructor interaction was the strongest predictor. Internet self-efficacy was a weak predictor that contributed little to satisfaction.

Table 6

Multiple Regression Analysis

\begin{tabular}{llllllll}
\hline Variables & $\mathrm{B}$ & $\mathrm{SE} \mathrm{B}$ & $\beta$ & $\mathrm{t}$ & $\mathrm{p}$ & \multicolumn{2}{c}{ Tolerance } \\
\hline (Constant) & -.220 & .455 & & -.483 & .631 & & \\
Learner-learner & .298 & .104 & .276 & 2.869 & $.006^{* *}$ & .777 & 1.287 \\
$\begin{array}{l}\text { Learner- } \\
\text { instructor }\end{array}$ & .715 & .133 & .598 & 5.361 & $.000^{* * *}$ & .580 & 1.725 \\
$\begin{array}{l}\text { Internet self- } \\
\text { efficacy }\end{array}$ & .040 & .098 & .041 & .414 & .681 & .718 & 1.392 \\
\hline
\end{tabular}

$* \mathrm{p}<.05 . * * \mathrm{p}<.01 . * * * \mathrm{p}<.001$ 
Research Question 3: What is the unique contribution of significant independent variables to student satisfaction?

To obtain the unique contribution of significant predictors to student satisfaction, hierarchical linear regression was performed by having each predictor entered in the last step of the regression. Table 7 reveals the unique variance each predictor contributes to student satisfaction after controlling for the influence of the other two predictors. Learner-instructor interaction, which is the strongest predictor, explained $20.7 \%$ of the variance in student satisfaction, while learner-learner interaction explained only about $5.9 \%$ of the variance of student satisfaction. Internet self-efficacy, which is not a significant predictor, contributes almost nothing to student satisfaction, with only $0.1 \%$ of the variance in satisfaction explained.

Table 7

Unique Contribution of Each Predictor

\begin{tabular}{llll}
\hline Variables & R square change & F change & Sig. F change \\
\hline Learner-learner interaction & .059 & 8.23 & $.006^{* *}$ \\
Learner-instructor interaction & .207 & 28.74 & $.000^{* * *}$ \\
Internet self-efficacy & .001 & .171 & .681 \\
\hline
\end{tabular}

$* \mathrm{p}<.05 . * * \mathrm{p}<.01 . * * * \mathrm{p}<.001$

\section{Discussion}

Although both learner-learner and learner-instructor interactions were significant predictors for student satisfaction, learner-instructor interaction was the most influential factor. Internet self-efficacy was not found to be a significant predictor for student satisfaction. Explanations and discussions about these major findings were provided.

\section{Learner-Instructor Interaction is the Most Important Contributor to Student Satisfaction}

Learner-learner interaction and learner-instructor interaction were two significant components in the prediction of student satisfaction in this study. This result is aligned with the findings of studies conducted by Battalio (2007) and Bolliger and Martindale (2004). Both studies found that learner-instructor interaction and learner-learner interaction were important indicators of student satisfaction. Although both types of interaction were significant predictors, learner-instructor interaction was the stronger predictor when compared to learner-learner interaction. This finding seems to make sense for the following reasons. First, according to Skylar (2009), the advantages of 
using synchronous (e.g., Interwise) learning tools include real time knowledge sharing and immediate access to the instructor for questions or comments. In this study, lecturing was the main activity. Instructors served as the major content delivery person; they offered live lectures and/or initiated questions and other class activities. As the synchronous sessions did not involve student collaboration projects, students may have had lower communication with classmates than the instructor. It corresponds to some previous studies indicating that the integration of collaborative projects or assignments would enable conversation, discussion, or negotiations among learners in terms of social constructivism (J ung, Choi, Lim, \& Leem, 2002; Woo \& Reeves, 2007)

Second, in this study the instructor was the main moderator who controlled the teaching processes in Interwise synchronous environments. Interwise, mainly designed to support learner-instructor interaction, provides very limited interaction opportunities for participants ( $\mathrm{Ng}, 2007)$. Interwise is more like an instructor-led platform. Consistent with Ng's (2007) study where students perceived that their interaction with classmates was extremely limited, learner-learner interaction did not contribute very much to student satisfaction in this study, even though learner-learner interaction was a significant predictor. In addition, the three features that students favored using most in Interwise (i.e., emotion icons, raise hand, and send note) would help explain the significance of learner-instructor interaction in this context (please see Table 2). These features allow students to respond to the instructor by asking questions or receiving files from the instructor. One interesting finding was that emotion icons seemed to be one of the most popular features that students preferred to use when communicating with their instructor. Findings of previous studies indicated that use of emoticons increased motivation and interactive learning experiences in elearning environments as emoticons were often used as visual or social cues that provide additional information behind the text (Tung \& Deng, 2007; Wolf, 2000).

Third, it was the first time students utilized Interwise. Students only used Interwise for two sessions out of one semester class. They might still have explored how to interact with the instructor or their classmates through the Interwise features. Given this, students might have been more inclined to follow the directions from the instructor, instead of being very active in interacting with their classmates. As Reushle and Loch (2008) suggested, training and technical support are critical for the successful use of web-conferencing tools.

Last, culture and approaches to learning may play a role in the finding of our study that learner-instructor interaction was the strongest predictor. Chinese students tend to learn by rote and repetition. They prefer a teacher-centered style of teaching by which knowledge is transmitted directly from the instructor (Wong, 2004). Western pedagogy that favors a constructivist approach and participative style of learning is less acceptable to Chinese students than Western students. Chinese students would be more active in one-to-one interaction with the instructor especially when the instructor initiates the 
questions to students (Levinsohn, 2007). The preference of teacher-centered learning approaches may result in more student interaction with the instructor than with peers.

\section{Internet Self-Efficacy is Correlated with but Not Predictive of Student Satisfaction}

Even though most students in the class seemed to possess a certain level of confidence in utilizing Internet-based technologies, Internet self-efficacy was not a significant predictor of student satisfaction. This result corresponds to Rodriguez Robles's (2006) research where Internet self-efficacy did not significantly contribute to student satisfaction. Interwise may not require a high level of skill in performing Internetrelated tasks, so the variance of Internet self-efficacy among students might have been reduced and therefore failed to impact satisfaction in the presence of the other predictors. Most students had neutral Internet self-efficacy and were able to use Interwise smoothly, which in turn may have led to the non-significant impact on student satisfaction. Moreover, when looking into the years of computer usage (please see Table 1) among these students, about $70 \%$ of them have been using computers for more than 7 years, which may have led to the fact that most students' confidence in performing Internet required activities was on an average level.

Among the eight Internet self-efficacy items, learners seemed to have a higher level of confidence when relating to their confidence in gathering data $(M=5.59)$ through the Internet and getting support through online discussion when necessary $(M=5.10)$. Learners' confidence level dealing with Internet hardware trouble-shooting $(\mathrm{M}=4.12)$ and identification of failed Internet-related tasks $(\mathrm{M}=4.04)$ was typically lower than the responses for the rest of the Internet self-efficacy survey items. However, the average scores of these two items were still above the median score (4.0). Scheduling a training session before the synchronous sessions start would likely be helpful to those students who have lower confidence in using the Internet and the web-based conferencing tool, as suggested by Torkzadeh and Van Dyke (2002) that training is an approach to improving one's Internet self-efficacy.

\section{Conclusion and Implications}

Overall, learners seemed to be moderately satisfied with the online synchronous sessions through the use of the Interwise platform. It was not difficult for them to use Interwise for course related activities during the class. Learners perceived more interaction with their instructor than with classmates during the two-week long online sessions. The combination of learner-instructor interaction, learner-learner interaction, and Internet self-efficacy significantly contributed to student satisfaction. Learnerlearner and learner-instructor interactions were significant predictors of student satisfaction, while Internet self-efficacy barely had an influence on student satisfaction. 
Learner-instructor interaction was the strongest predictor of satisfaction, which corresponds to the design of instructor-led features embedded in Interwise.

According to the findings of this study, we suggest that (a) instructors should consider the features of technology tools they intend to utilize for the class, and employ appropriate pedagogies to enhance interaction among learners in synchronous learning environments; (b) learners' background with different cultures or learning approaches to learning should be taken into account while delivering course content synchronously; and (c) pre-class training should be offered to ensure learners' understanding about the features of the adopted technology so that their interaction with the instructor or peers would be enhanced.

\section{Limitations and Suggestions for Future Research}

This study is based on two sessions of online synchronous learning. If more such sessions could be implemented, there could have been more interactions among learners, which in turn might have increased the influence of learner-learner interaction on student satisfaction. In addition, other components, which are not included in this study, may influence student satisfaction, such as learner-content interaction, student autonomy, and class size. Researchers might consider including other components that have potential effect on student satisfaction in future studies.

Self-report was used in this study, which is a convenient way of measuring student perceptions of interaction, Internet self-efficacy, and satisfaction. However, self-report may not tell the whole story of how students interact with their instructor and classmates. Interviews and examinations of log files may be employed in future studies. Examinations of log files would further allow researchers to study student interactions with digital objects.

The participants of this study involved two cohorts who took this class in two different semesters. The instructor might have been more skilled in using Interwise during the second semester, which in turn may have influenced study results. For instance, any problems encountered in the first semester may not have occurred in the second semester, if the instructor knew how to solve students' problems quickly based on his previous experiences in the first semester. 


\section{References}

Ali, A., \&Ahmad, I. (2011). Key factors for determining students' satisfaction in distance learning courses: A study of Allama Iqbal Open University. Contemporary Educational Technology, 2(2), 118-134.

Allen, I. E., \& Seaman, J . (2003). Sizing the opportunity: The quality and extent of online education in the United States, 2002 and 2003. Retrieved from https:// www.sloan-c.org/publications/survey/pdf/sizing_opportunity.pdf

Altun, S. A., Kalayci, E., \& Avci, U. (2011). Integrating ICT at the faculty level: A case study. The Turkish Online J ournal of Educational Technology, 10(4), 230-240.

Anderson, T. (2003). Modes of interaction in distance education: Recent developments and research questions. In M. G. Moore \&W. G. Anderson (Eds.), Handbook of distance education (pp. 129-144). Mahwah, NJ : Erlbaum.

Apena, T. T. (2012). Information and communication technology and open distance learning, impact and challenges. International J ournal of Social Sciences and Education, 2(1), 440-446.

AT\&T. (2013). Product Brief-AT\&T Connect Integrated Edition v9.5. Retrieved from http:// www.business.att.com/ content/productbrochures/PB_ConnectIEv 9.5.pdf

Bandura, A. (1977). Self-efficacy: Toward a unifying theory of behavioral change. Psychological Review, 84(2), 191- 215. doi:10.1037/0033-295X.84.2.191

Battalio, J . (2007). Interaction online: A reevaluation. Quarterly Review of Distance Education, 8(4), 339-352.

Biner, P. M., Bink, M. L., Huffman, M. L., \&Dean, R. S. (1997). The impact of remotesite group size on student satisfaction and relative performance in interactive telecourses. The American J ournal of Distance Education, 11(1), 23-33. doi:10.1080/08923649709526949

Bolliger, D. U., \& Martindale, T. (2004). Key factors for determining student satisfaction in online courses. International J ournal on E-Learning, 3(1), 61-67.

Bradley, L., Lindstrom, B., \& Rystedt, H. (2010). Rationalities of collaboration for language learning in a wiki. J ournal of Eurocall, 22(2), 247-265.

Bray, E., Aoki, K., \& Dlugosh, L. (2008). Predictors of learning satisfaction in J apanese online distance learners. International Review of Research in Open \& Distance Learning, 9(3), 1-24. 
Carter, J. F. (2009). Lines of communication: Using a Wiki in a mathematics course. PRIMUS, 19(1), 1-17.

DeTure, M. (2004). Cognitive style and self-efficacy: Predicting student success in online distance education. American J ournal of Distance Education, 18(1), 2138.

Eastin, M. S., \&LaRose, R. (2000). Internet self-efficacy and the psychology of the digital divide. Retrieved J anuary 14, 2009 from http://jcmc.indiana.edu/vol6/issue1/ eastin.html

Executive Yuan (2011). Surveys of ICT use and digital opportunity in Taiwan: Executive summary. Retrieved from http:/ / www.rdec.gov.tw/ public/ Data/2248494671.pdf

J oo, Y. J ., Bong, M., \& Choi, H. J . (2000). Self-efficacy for self-regulated learning, academic self-efficacy and Internet self-efficacy in web-based instruction. Educational Technology Research and Development, 48(2), 5-17. doi: 10.1007/ BF02313398

J ung, I., Choi, S., Lim, C., \& Leem, J . (2002). Effects of different types of interaction on learning achievement, satisfaction and participation in web-based instruction. Innovations in Education \& Teaching International, 39(2), 153-162. doi: $10.1080 / 14703290252934603$

Koustourakis, G., Panagiotakopoulos, C., \&Vergidis, D. (2008). A contribution to the hellenic open university: Evaluation of the pedagogical practices and the use of ICT on distance education. International Review of Research in Open and Distance Learning, 9(2), 1-18.

Kuo, Y. C., Eastmond, J . N., Schroder, K. E. E., \&Bennett, L. J . (2009, J une). Student perceptions of interactions and course satisfaction in a blended learning environment. Paper presented at ED-MEDIA 2009 World Conference on Educational Multimedia, Hypermedia \& Telecommunications, Honolulu, HI.

Kuo, Y. C., Walker, A., Belland, B. R., \& Schroder, K. E. E. (2013). A predictive study of student satisfaction in online education programs. The International Review of Research in Open and Distance Learning, 14(1), 16-39.

Kuo, Y. C., Walker, A., Schroder, K. E. E., \& Belland, B. R. (2014). Interaction, Internet self-efficacy, and self-regulated learning as predictors of student satisfaction in online education courses. The Internet and Higher Education, 20, 35-50. doi:10.1016/j.iheduc.2013.10.001 
Levinsohn, K. R. (2007). Cultural differences and learning styles of Chinese and European trades students. Institute for Learning Styles J ournal, 1, 12-22.

Lim, C. K. (2001). Computer self-efficacy, academic self-concept, and other predictors of satisfaction and future participation of adult distance learners. American J ournal of Distance Education, 15(2), 41-51. doi: 10.1080/08923640109527083

Moore, M. G. (1989). Three types of interactions. The American J ournal of Distance Education, 3(2), 1-6.

Moore, M. G., \& Kearsley, G. (1996). Distance education: A systems view. New York: Wadsworth.

Muirhead, B., \&J uwah, C. (2004). Interactivity in the computer-mediated college and university education: A recent review of literature. Educational Technology \& Society, 7(1), 12-20.

Ng, K. C. (2007). Replacing face-to-face tutorials by synchronous online technologies: Challenges and pedagogical implications. International Review of Research in Open and Distance Learning, 8(1). Retrieved from http:// www.irrodl.org/index.php/irrodl/article/ view/ 335

Northrup, P., Lee, R., \& Burgess, V. (2002). Learner perceptions of onlineinteraction. Paper presented at ED-MEDIA 2002 world conference on educational multimedia, hypermedia \& telecommunications, Denver, CO.

Offir, B., Lev, Y., \& Bezalel, R. (2008). Surface and deep learning processes in distance education: Synchronous versus asynchronous systems. Computers and Education, 51(3), 1172-1183. doi: 10.1016/j.compedu.2007.10.009

Olusola, A. J ., \&Alaba, S. O. (2011). Globalizationm, information and communication technologies (ICTs) and open/ distance learning in Nigeria: Trends, issues and solution. Turkish Online J ournal of Distance Education, 12(3), 66-77.

Puzziferro, M. (2006). Online technologies self-efficacy, self-regulated learning, and experiential variables as predictors of final grade and satisfaction in collegelevel online courses. Dissertation Abstracts International, 66(12). (UMI No. 3199984)

Puzziferro, M. (2008). Online technologies self-efficacy and self-regulated learning as predictors of final grade and satisfaction in college-level online courses. American J ournal of Distance Education, 22(2), 72-89. doi: 10.1080/08923640802039024 
Reushle, S., \& Loch, B. (2008). Conducting a trial of web conferencing software: Why, how, and perceptions from the Coalface. Turkish Online J ournal of Distance Education, 9(3), 19-28.

Rodriguez Robles, F. M. (2006). Learner characteristic, interaction and support service variables as predictors of satisfaction in Web-based distance education. Dissertation Abstracts International, 67(07). (UMI No. 3224964).

Rogerson-Revell, P. (2007). Directions in e-learning tools and technologies and their relevance to online distance language education. Open Learning, 22(1), 57-74.

Salmon, G. (2000). E-moderating: The key to teaching and learning online. London: Kogan Page.

Skylar, A. A. (2009). A comparison of asynchronous online text-based lectures and synchronous interactive web conferencing lectures. Issues in Teacher Education, 18(2), 69-84.

Snowball, J ., \& Mostert, M. (2010). Introducing a learning management system in a large first year class: Impact on lecturers and students. South African J ournal of Higher Education, 24(5), 818-831.

Thompson, L. F., Meriac, J . P., \& Cope, J . G. (2002). Motivating online performance: The influences of goal setting and Internet self-efficacy. Social Science Computer Review, 20(2), 149-160. doi:10.1177/089443930202000205

Torkzadeh, G., Chang, C. J ., \&Demirhan, D. (2006). A contingency model of computer and Internet self-efficacy. Information \&Management, 43(4), 541-550. doi:10.1016/j.im.2006.02.001

Torkzadeh, G., \& Van Dyke, T. P. (2002). Effects of training on Internet self-efficacy and computer user attitudes. Computers in Human Behavior, 18(5), 479-494. doi:10.1016/S0747-5632(02)00010-9

Tsai, M. J ., \& Tsai, C. C. (2003). Information searching strategies in web-based science learning: The role of Internet self-efficacy. Innovations in Education \& Teaching International, 40(1), 43-50. doi:10.1080/ 1355800032000038822

Tung, F. W., \& Deng, Y. S. (2007). Increasing social presence of social actors in elearning environments: Effects of dynamic and static emoticons on children. Displays, 28(4/5), 174-180.

Wang, Q. (2008). A generic model for guiding the integration of ICT into teaching and learning. Innovations in Education and Teaching International, 45(4), 411-419. 
Wang, C. C., \& Ku, H. Y. (2010). A case study of an affective education course in Taiwan. Educational Technology Research and Development, 58, 613-628. doi:10.1080/14703290802377307

Wang, Q. \& Woo, H. L. (2007). Systematic planning for ICT integration in topic learning. Educational Technology \&Society, 10(1), 148-156.

Wolf, A. (2000). Emotional expression online: Gender differences in emoticon use. Cyberpsychology \& Behavior, 3(5), 827-833. doi:10.1089/ 10949310050191809

Wong, K. K. (2004). Are the learning styles of Asian international students culturally or contextually based? International Education J ournal, 4(4), 154-166.

Woo, Y., \& Reeves, T. C. (2007). Meaningful interaction in web-based learning: A social constructivist interpretation. Internet and Higher Education, 10, 15-25. doi:10.1016/j.iheduc.2006.10.005

Yukselturk, E., \&Yildirim, Z. (2008). Investigation of interaction, online support, course structure and flexibility as the contributing factors to students' satisfaction in an online certificate program. Educational Technology \& Society, 11(4), 51-65.

\section{Athabasca University $\mathbf{A}$}

(ㄷ) $(0)$ 